\title{
Exploring the Effectiveness of Two Types of Virtual Reality Headsets for Teaching High School Mathematics
}

\author{
Yi Chen Hsu ${ }^{1 *}$ \\ ${ }^{1}$ National Taipei University of Education, TAIWAN \\ Received 27 May 2020 • Accepted 30 May 2021
}

\begin{abstract}
This study examines the integration of virtual reality (VR) information technology in the teaching of systems of linear equations in three variables in a high school mathematics class. More broadly, the study investigates the effectiveness of digital teaching with respect to the learning process. The study tests two auxiliary teaching systems: a desktop-based VR system and an all-in-one VR system. Before and after the experiment, participants were asked to complete a questionnaire, and post-experiment interviews were conducted with both students and teachers, both of which provided quantitative and qualitative data for analysis. The result of data show that VR technology is a suitable tool for teaching high school mathematics, when it combined with the tradition curriculum were well-received and facilitate effective learning. In addition, the desktop-based VR system is found to be superior to the all-in-one VR system in terms of learning effectiveness since the high-efficiency display and better control.
\end{abstract}

Keywords: virtual reality, high school mathematics, digital teaching, learning effectiveness

\section{INTRODUCTION}

Mathematics is highly relevant to daily life owing to its common usage. Hence, the extent of a person's understanding of mathematics has important implications. The process of learning mathematics should reflect a person's real-life experiences. Virtual Reality (VR) is a technological display tool that allows users to be placed in a virtual world in which situations that are otherwise difficult to present can be created. For example, through VR, it is possible to present mathematical equations in a novel way, thereby strengthening the learning process. To date, information technology has given rise to various teaching technologies and media, which have shaped teaching methods (Martin, Gollan, \& Grigg, 2011). Through the development of digital technology, learning is no longer limited to paper textbooks. To date, VR has been integrated into the teaching of many subjects, including music (Degli et al., 2019), anatomy (Jang et al., 2017), neurosurgery (Pelargos et al., 2017), and architecture (Abdullah et al., 2017), as well as training educators (Lim et al., 2019). The central goal of the present study is to investigate whether VR teaching can be used to help students effectively learn abstract mathematics.

\section{Research Background and Motivation}

Video media and VR technology can be used as auxiliary teaching material, making the learning process livelier and more interesting. When learning to solve systems of linear equations in three variables, high school students must determine eight intersecting situations formed by three planes (see Figure 1). This includes a situation in which the three planes intersect at a single point, intersect at a straight line, or fail to intersect at all. Teachers report that students often struggle to comprehend the eight intersecting situations formed by three planes from the graphics found in textbooks, or commonly misunderstand the crosslinking methods presented by the graphics. Therefore, this study envisions the use of VR to present the eight types of intersection formed by three planes more clearly. The hope is that this may allow students to build a clearer understanding of the possible cross-linking of planes to eventually introduce systems of linear equations in three variables.

Current VR devices can be divided into three categories according to hardware type: desktop-based VR, mobile-based VR, and all-in-one VR. Desktop-based

(c) 2021 by the authors; licensee Modestum. This article is an open access article distributed under the terms and conditions of the Creative Commons Attribution License (http://creativecommons.org/licenses/by/4.0/). 


\section{Contribution to the literature}

- The results show that VR technology is suitable for use in high schools as an auxiliary mathematics teaching tool.

- VR technology can be used for digital teaching of mathematics and has been shown to increase the effectiveness of learning.

- A desktop-based VR system is superior to an all-in-one VR system in regard to learning effectiveness.

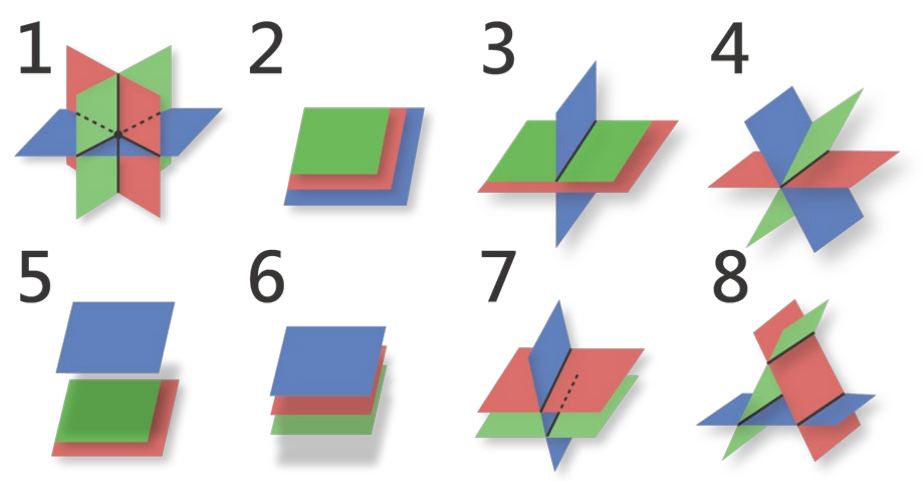

Figure 1. The eight possible intersecting situations of three planes

VR can provide a truly immersive VR experience involving head-mounted displays tethered to a powerful computer (e.g., Oculus Rift, HTC VIVE). Yet with high performance naturally comes high price and limited space. An all-in-one VR is a mid-range option that relies on an independent CPU, as well as input and output display functions. Although all-in-one VR, unlike desktop-based VR, does not require tethering to a computer and has lower space constraints, the operational experience and display are generally inferior. Mobile-based VR is an entry-level product that relies on VR headsets, such as Google Cardboard and Samsung Gear VR. The main advantage of this form of VR is its relatively low price and convenient operation. However, this product is often less comfortable to wear, and the viewing quality is sometimes poor and can cause dizziness, precluding the use of this type of VR for games. Amin et al. (2016) indicated that despite the simplicity of mobile-based VR and the small screen size, this category of VR is capable of providing a satisfactory level of immersion compared to desktop-based VR. Low-cost VR, such as mobile-based VR, can be made available to students, facilitating interactive, personalized, and immersive learning experiences (Amer \& Peralez, 2014; Ball \& Johnsen, 2016). Therefore, low-cost VR offers the chance to enhance cross-domain learning, which itself demands further study (Castelvecchi, 2016). Although, Moro et al. (2017) found no significant differences in test scores when evaluating desktop-based VR and mobile-based VR, 40\% of participants experienced significantly higher rates of nausea and blurred vision when using mobile-based VR. To the best of our knowledge, no research exists that compares the learning efficacy of desktop-based VR and mobile-based VR.
To increase student participation and interest in STEM (Science, Technology, Engineering, and Mathematics) subjects, primary and secondary schools have adopted various innovative technology-enhanced learning methods. VR is a relatively advanced technology that can be used to present various scenes and concepts in a virtual environment, enabling students to more easily grasp complex concepts and definitions (Bogusevschi et al., 2020). Teachers use VR technology to prepare classroom lessons that support student-centered teaching and personalized learning (Yildirim et al., 2020). In another study, 28 secondary school students reported increased positive attitudes and interest toward mathematics following the use of VR (Simsek, 2016).

This study develops a set of VR auxiliary teaching systems to support the teaching of systems of linear equations in three variables to high school mathematic students. The technology involves a learning program entitled "Learning the System of Linear Equations in Three Variables from Escher's Optical Illusion." A desktop-based VR system and an all-in-one VR system are built to explore whether VR is suitable as a means of digital auxiliary teaching. Of the two sets of VR systems, the desktop-based VR showed good performance but was limited in terms of space usage, while the all-in-one VR showed a satisfactory performance but was easier to use and operate. We discuss which of the two technologies is better with respect to student learning outcomes.

This paper expands on the use of the Learning the Systems of Linear Equations in Three Variables from Escher's Optical Illusion teaching material as well as insights from a previous study (Hsu, 2020), further to compare the impact of two types of VR headsets on students' learning effectiveness. The teaching system 
extends Escher's paintings Ascending and Descending and Waterfall into 3-D optical illusion animations. Students are able to observe shapes from different angles, allowing them to overcome misunderstandings caused by the original teaching method, which relies solely on graphics displayed in textbooks.

The use of VR in the classroom can therefore increase students' interests and creativity by allowing them to take virtual trips, which in turn fosters motivation, improves scientific and technological literacy, and promotes individualized learning (Yildirim et al., 2020).

\section{Research Questions}

This study integrates VR into the teaching of the systems of linear equations in three variables and explores the following research questions:

1. Is VR technology suitable for use in teaching systems of linear equations in three variables?

2. When VR is used to teach systems of linear equations in three variables, is learning effectiveness improved?

3. Which of two candidate VR headsets, desktopbased and all-in-one, improves students' learning effectiveness to a greater extent?

\section{LITERATURE REVIEW}

According to the present research aims, this section presents a review of the existing literature and technology to explore the integration of information technology into teaching, VR, and learning effectiveness.

\section{The Integration of Information Technology into Teaching}

In recent years, influenced by the theory of constructive learning, the goal of computer-assisted learning has evolved and is no longer simply aimed at encouraging students to participate unilaterally. Rather, constructive learning now seeks to enable students to manipulate learning content independently. In this manner, students may generate an active internal motivation to learn and may actively clarify, summarize, and overcome areas of misunderstanding. Students may be able to meet teaching goals sought by the learning materials and construct basic concepts on their own. The development of cognitive theory also promotes the application of interactive simulations in education (Fan \& Geelan, 2012).

The integration of information technology into teaching can foster motivation for learning and facilitate the easy and rapid sharing of teaching materials. The method of application is not limited to the application of computers or software, as technology can be integrated into various teaching resources to accelerate learning, such as in the teaching of foreign languages (Liu, 2009) or natural sciences (Looi et al., 2011). Research has

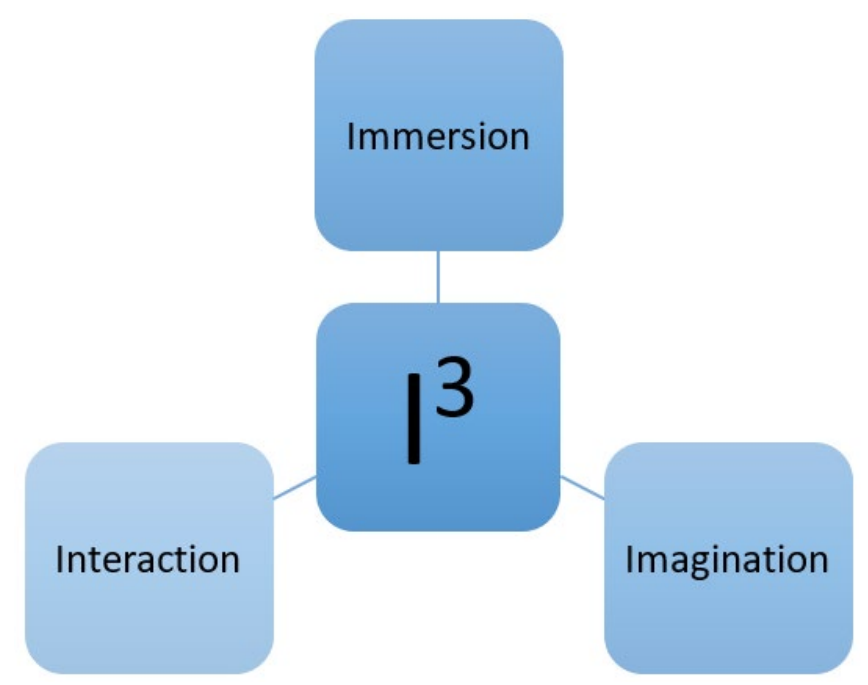

Figure 2. VR Triangle (Burdea, 1993)

shown that learning motivation can be improved, the learning process can be made more enjoyable, and learners can be helped to improve their skills (Chen \& $\mathrm{Hsu}, 2008)$. Ruchter et al. (2010) used computers to create environmental education activities, finding that the use of action guidance systems increased students' environmental knowledge and enhanced students' motivation to learn. Many scholars even used the virtual world "Second Life" to create 3D objects to teach abstract concepts (Merchant et al., 2012). Kaufman (2006) applied augmented reality (AR) and VR to the study of geometry among six-year-olds. They concluded that students and teachers were open to this form of learning.

This research makes use of computer generation technology, allowing students to clearly view compositions simulated via VR, namely the aforementioned eight intersecting situations formed by three planes. The aim is to help students better understand geometric shapes that are often difficult to imagine when viewed as a graphic in a textbook.

\section{Virtual Reality}

VR is a virtual world that uses computer simulation to generate $3 \mathrm{D}$ space, providing users with immersive visual and other sensory simulations. VR enables us to produce near-realistic simulation experiences and create scenes that are impossible to produce in the real world, while simultaneously avoiding the dangers that may be encountered in an equivalent real-world situation (Sherman \& Craig, 2003). Burdea (1993) described VR as a computer-generated program that simulates and interacts instantly with a variety of sensory information; it possesses three characteristics: "immersion," "interaction," and "imagination" (Figure 2).

As the costs have decreased year on year, VR has gradually become mainstream, and many big tech companies have launched VR devices and applied the technology in a variety of industries, such as military, medicine, education, construction, entertainment, and 
tourism (Wexelblat, 2014). Brown et al. (1989) claimed that knowledge exists in the context of learning and learning activities. Learners must actively interact to contextualize knowledge and develop their understanding. Learning situations can be simulations of real-world situations or abstract symbolic logic environments. It is preferable for learners to develop knowledge and skills in real situations. VR technology can provide learners with virtual learning situations, allowing them to interact with knowledge during use and to develop their knowledge. As McLellan (1994) argued, a learning situation can be real or virtual, and the learner can learn from a context generated by a computer. In this way, VR can provide the learner with the opportunity to actively operate and repeatedly practice a given task.

Since its introduction, the application of VR technology has garnered significant interest. VR technology allows for simulations and 360-degree videography and photography and can be accessed through devices such as head-mounted display devices, data gloves, and bodysuits (Black, 2017). The technology has gained particular attention in the field of education. Schools offering K-12 and higher education are adopting VR technology to, for example, send their students on an expedition around the world via virtual field trips. In 2015, Google launched the Expeditions VR system for K12 classrooms. Unlike Google Cardboard and other VR apps that offer a single-user VR experience, Google Expedition is affordable (Lee et al., 2017). VR applications are used in teaching mostly for adult training or higher education and are rarely designed for children under 10 years of age. Nevertheless, there are examples of VR being used in middle school for students aged 10-17 (Freina \& Ott, 2015), such as Vfrog ${ }^{\mathrm{TM}}$, which teaches students virtual frog anatomy (Lee et al., 2010). $M^{M A T}{ }^{3 D}$ is another example of VR applied in education in this case to teach high school-level mathematics (Pasqualotti \& Freitas, 2002), while DimensionM ${ }^{\mathrm{TM}}$ offers students the chance to complete a series of tasks using mathematical principles in a gamified journey (Kebritchi et al., 2010). Furthermore, previous studies investigate the students learning motivation and effectiveness of applying VR to the systems of linear equations in three variables (Hsu et al., 2018; Hsu, 2020). VR also plays an important role in virtual laboratory technology (Heradio et al., 2016), as it can be applied to various experiments that cannot otherwise be demonstrated in disciplines such as physics or chemistry. Even more noteworthy is that the use of virtual laboratory technology has been shown to produce similar or higher levels of learning compared with traditional laboratory teaching (Brinson, 2015).

Currently, the VR presentation method requires head-mounted displays for displaying simulated images and projecting them onto the user's retina. Desktopbased VR requires an external high-end computer to supplement the deficiencies of computing components, and currently, the price remains too high to attract general consumers. Low-cost prices have been key in making VR more accessible to schools (Yildirim et al., 2020). The emergence of all-in-one VR in 2018 allowed VR devices to become available to the mass market without connecting mobile phones and computers (Tseng, 2018). Top-quality VR can bring a more immersive and interactive experience, while supporting six degrees of freedom (6DoF) tracking, like desktopbased VR. Although high-end VR is relatively weak in terms of the immersive experience, it can still support viewing and relatively simple game experiences with video as the core requirement, like all-in-one VR (Cheng \& Hong, 2018). The optimal VR system for enabling learning among students is also discussed in this study, and the resulting insights can be used as a reference for schools considering VR procurement in the future.

\section{Learning Effectiveness}

Learning effectiveness refers to the performance of learners after participating in a given set of learning activities for a period. Widely recognized as a measure of learning effectiveness, the degree to which students achieve teaching goals and understand teaching is analyzed via multiple evaluation methods.

Bloom's Taxonomy of Learning (Anderson et al., 2001) is often used to test students' learning effectiveness. It consists of six cognitive levels of complexity and considers a wide range of factors that affect teaching, which are defined as follows:

1. Remember: recall facts and basic concepts.

2. Understand: explain ideas or concepts.

3. Apply: use information in new situations.

4. Analyze: draw connections among ideas.

5. Evaluate: justify a stand or decision.

6. Create: produce new or original work.

In the cognitive domain, lower levels in the revised version consist of "remember," "understand," "apply," and "analyze." Higher levels consist of "evaluate" and "create." Remembering and learning retention are closely related, while the other five are related to learning transfer (Krathwohl, 2002). To confirm whether students have achieved their intended goals, after confirming the teaching goals and related curriculum design, teachers may analyze educational goals and the substantive meaning of teaching activities individually, according to the theoretical framework laid out in Bloom's Taxonomy of Learning.

There are two types of learning effectiveness, short term learning to measure the learning goal of the course and long-term learning to evaluate the overall educational program and future working life (Moody \& Sindre, 2003). According to the course purpose of systems of linear equations in three variables, this study evaluates the short-term learning in the context of the 


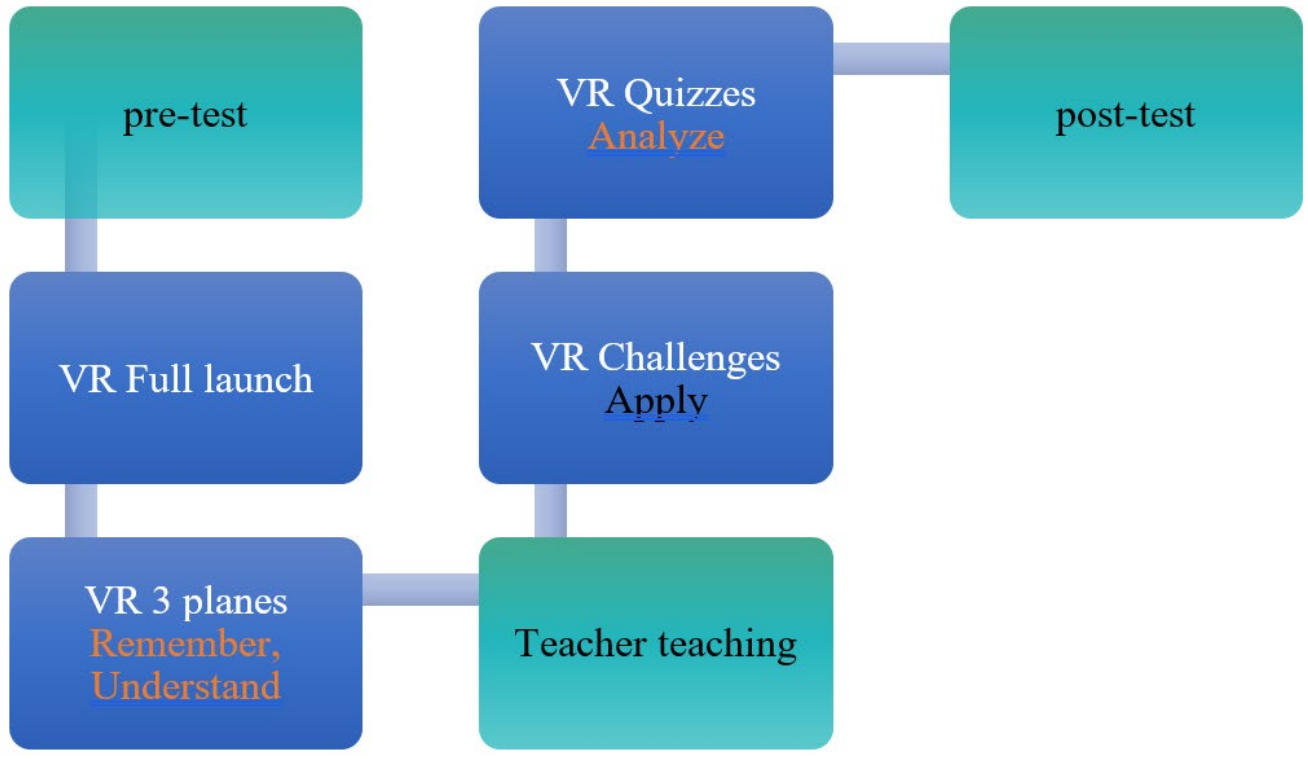

Figure 3. Experimental teaching process

course, and applies the four levels of remember, understand, apply, and analyze to the teaching objectives. Therefore, this study follows a four-level cognitive domain, and high school teachers are engaged to jointly develop and design the items of the experimental questionnaire. The questionnaire comprises six questions, with each level having one or two associated questions.

\section{RESEARCH METHOD}

In this study, experimental research design and questionnaire surveys were used to collect the data needed for the research. One cohort used a desktopbased VR system (HTC VIVE) for VR auxiliary teaching, while the other used an all-in-one VR system (HTC VIVE Focus). The experimental procedure was the same across both cohorts (see Figure 3). First, subjects were asked to fill in a pre-test questionnaire and then enter the two VR teaching units (VR full launch, VR three planes) where they imported practical teaching material. After the teaching session, two VR test units (VR Quizzes, VR Challenges) were conducted, a post-test questionnaire was distributed, and a short interview was conducted. Both the teaching unit and the questionnaire design incorporated the first four levels of Bloom's Taxonomy of Learning as research tools. After the questionnaires were collected, statistics were used to analyze and study the teaching systems.

\section{Research Subjects}

The teaching content of this study was "High School Mathematics 2-3 Systems of Linear Equations in Three Variables." One class of students comprising 24 boys and 6 girls formed the experimental group. The students used a desktop-based VR auxiliary system for the test, and we received 30 valid completed questionnaires. The other class, comprising 10 boys and 2 girls, formed the control group, which used the all-in-one VR auxiliary system for testing. We received 12 valid questionnaires from the students. The approximate times for each group were 15 minutes for the pre-test, 30 minutes for the first two VR teaching units, 40 minutes of teaching, 30 minutes for the last two VR test units, and 25 minutes for the post-test and interview. Including intermediate rest times, the entire procedure for each group lasted approximately 150 minutes.

\section{Research Tools}

The questionnaire design referred to the cognitive domains laid out in Bloom's Taxonomy of Learning revised by Anderson et al. (2001) (i.e., remember, understand, apply, analyze, evaluate, and create). This study used four domains-remember, understand, apply, and analyze - to develop the measurement tool of this study.

In terms of VR system devices, this study uses HTC VIVE as the experimental group device and HTC VIVE Focus as the control group device. Table 1 presents a comparison of the two devices. The advantage of HTC VIVE lies in the high-efficiency display screen and two six-degrees-of-freedom handles, which allow users to have a higher level of immersion; the disadvantage is that the helmet needs to be connected to a high-end PC; hence, the range of use will be limited by the length of the connecting line between the helmet and the PC. The advantage of HTC VIVE Focus is that there is no need to connect an external computer and mobile phone; the operation is therefore free and not limited by the length of the cable. The disadvantage is that the display effect is not as good, as there is only a three-degree-of-freedom handle for the operation, so the operation is less intuitive. 
Table 1. Comparison of HTC VIVE and HTC VIVE Focus

\begin{tabular}{|c|c|c|}
\hline 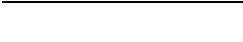 & HTC VIVE & HTC VIVE Focus \\
\hline \multicolumn{3}{|l|}{ Device } \\
\hline Features & Requires connection to a high-end PC. & Can be worn and operated independently \\
\hline Track & $\begin{array}{l}32 \text { receiver positioning, tracking area } 4 \mathrm{M} \times 3 \mathrm{M} \text {, } \\
\text { accurate }\end{array}$ & Inside-out, used within a certain range, inaccurate \\
\hline Screen & $\begin{array}{l}\text { Monocular } 1080 \text { p AMOLED, screen update rate is } \\
90 \mathrm{~Hz} \text {, viewing angle is } 110 \text { degrees }\end{array}$ & $\begin{array}{l}\text { 3K AMOLED, screen update rate is } 75 \mathrm{~Hz} \text {, viewing } \\
\text { angle is } 110 \text { degrees }\end{array}$ \\
\hline Handle & two & one \\
\hline Handle Sensing & six-degrees-of-freedom & three-degrees-of-freedom \\
\hline Platform & Steam VR and VIVEPORT & VIVE Ware \\
\hline
\end{tabular}

(Modified from $\mathrm{Wu}, 2017$ )

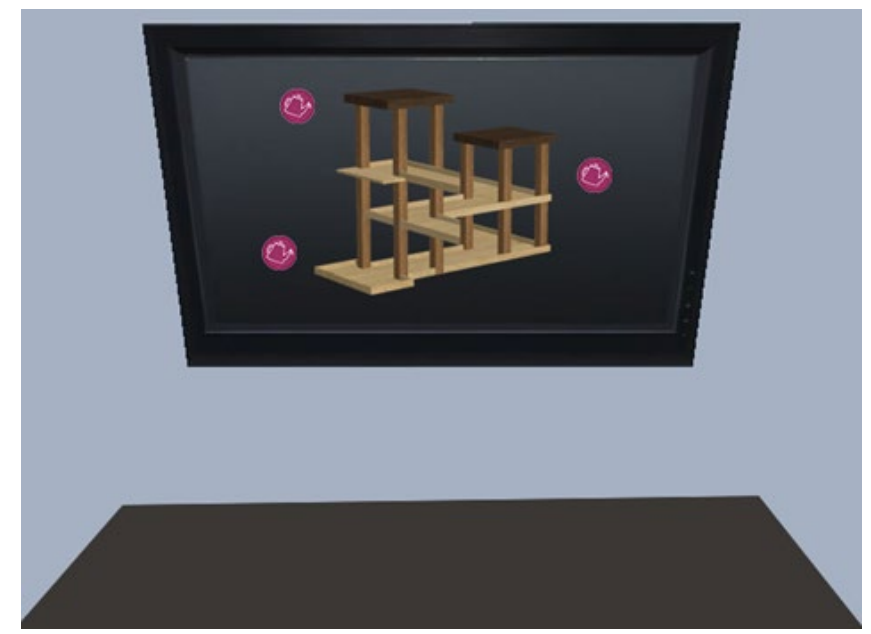

Figure 4. VR full launch

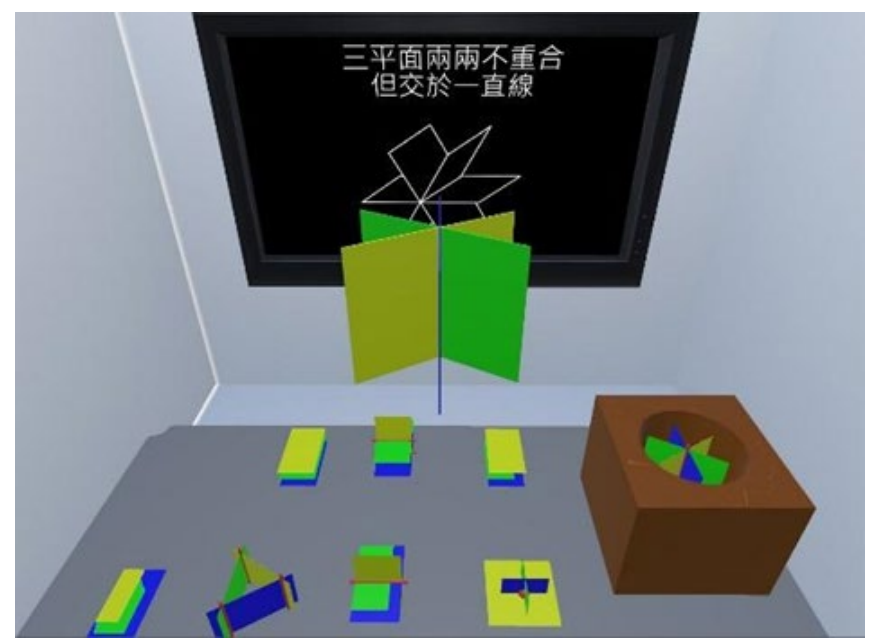

Figure 5. VR 3 planes

\section{Experiment Design}

This research used a self-developed VR mathematics auxiliary system called Learning the System of Linear

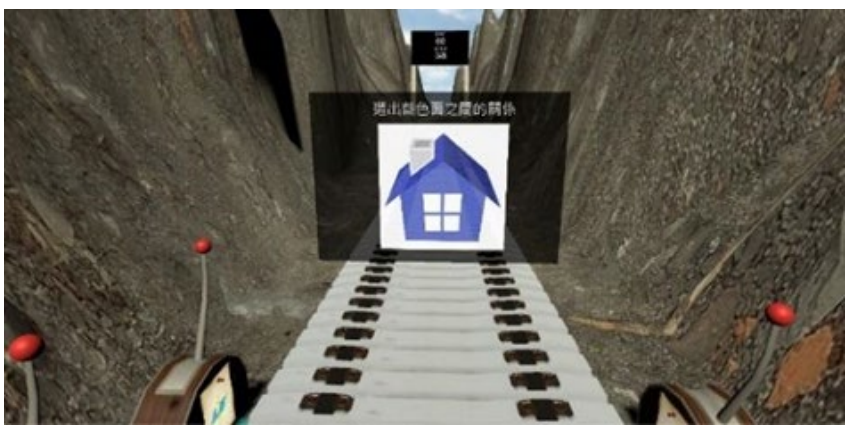

Figure 6. VR challenges

Equations in Three Variables from Escher's Optical Illusion as an experimental tool. This system consists of a set of mathematics tutorial materials for learning systems of linear equations in three variables via the visual simulation of Escher's illusional geometry model. It is produced by Unity and 3Ds Max and operated on HTC VIVE. The actual operation process consists of five steps: (1) VR Full launch (Figure 4): Two interactive units are used to create geometric animations of Escher's illusion to enhance learning motivation; (2) VR 3 planes (Figure 5): An interactive unit consisting of eight interactive situations of three planes allows students to fully understand the interlaced relationship of the three planes; (3) teacher-directed learning: this involves the mathematics teachers teaching a system of linear equations in three unknown units. The teaching content aims to spark the students' learning motivation and explain the problem-solving aspect of the activity; (4) VR Challenges (Figure 6): Gameplay image solving unit; and (5) VR Quizzes (Figure 7): Gameplay equation solving unit. 


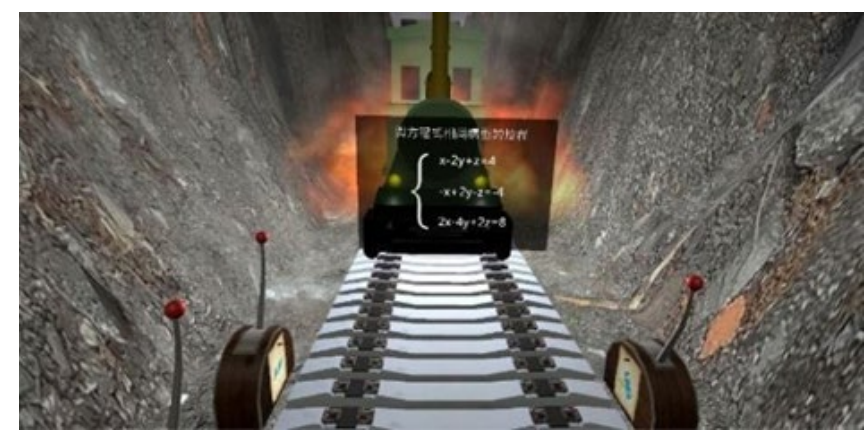

Figure 7. VR quizzes

Always-on information on screen should be used with care to avoid overloading visual information and creating distractions (Ruijten et al., 2018). This is particularly relevant for students who have never used a VR headset previously (Innocenti et al., 2019). Therefore, information in the VR scene used in this study is connected to the virtual interface and objects. Also, as the two VR devices (HTC VIVE and HTC VIVE Focus) used in this research have slightly different handling controls, the teaching materials are revised according to differences in the operation methods of either device, although the two versions of the teaching content and unit are the same. Table 2 shows a comparison of the operation differences.

Both groups were asked to fill out questionnaires before and after the experiment to measure the effectiveness of learning. Additional questions were included in the post-test questionnaire to measure the satisfaction level of the students with regard to the VR systems.

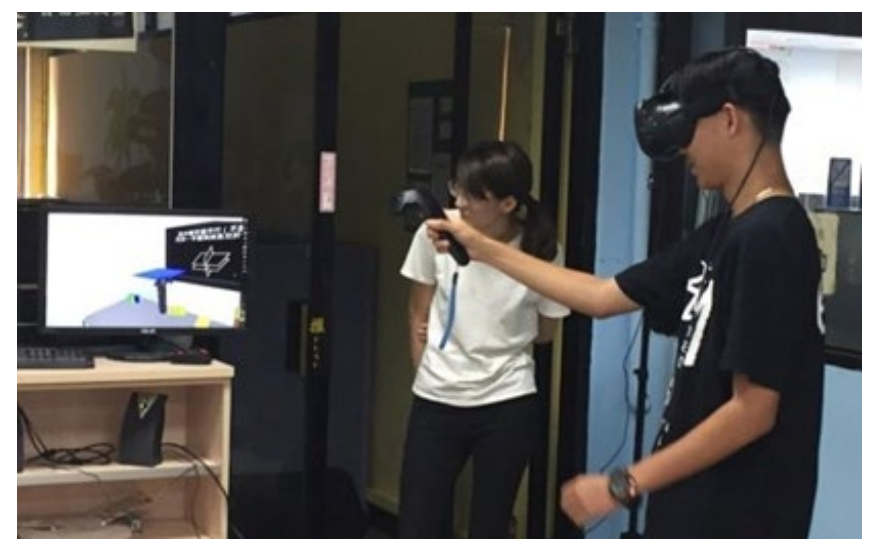

Figure 8. A student experiencing the desktop-based VR auxiliary system

\section{Experiment Process}

The process of testing was performed according to the five units described above: the first two VR units (Unit 1 and 2) lasted approximately 30 minutes, and the last two VR units (Unit 4 and 5) lasted approximately 30 minutes. Students who experienced the desktop-based VR auxiliary system were required to wear an HTC VIVE helmet and use a handheld operating handle. Researchers observed the progress of the students from the projection screen and provided guidance (Figure 8). Otherwise, students using the all-in-one VR auxiliary system were required to wear the HTC VIVE Focus helmet and use a handheld operating handle. Owing to the tracking and positioning of the device, students were required to be seated, while researchers positioned at the

Table 2. Comparison of VR Auxiliary Systems on HTC VIVE and HTC VIVE Focus

\begin{tabular}{llll}
\hline VR units & HTC VIVE control image & HTC VIVE Focus control image \\
\hline VR full launch & \\
VR 3 planes challenges & & \\
\hline
\end{tabular}




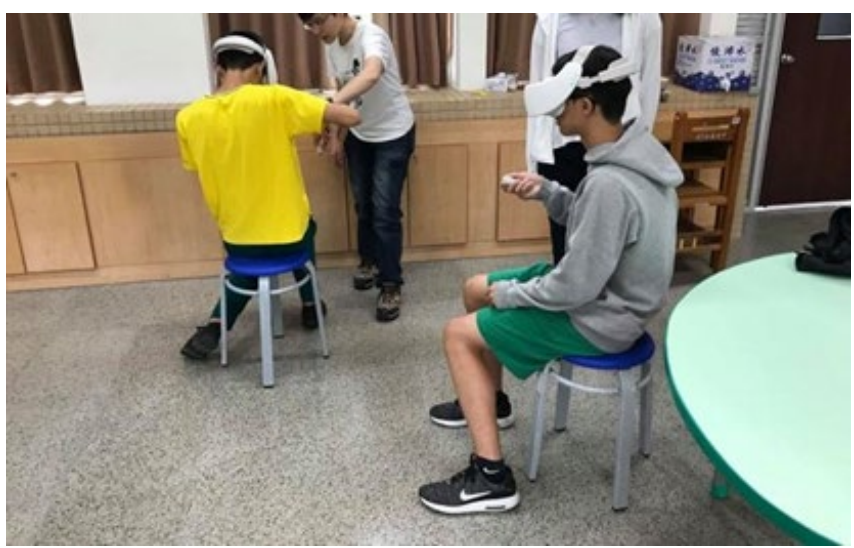

Figure 9. Students experiencing the all-in-one VR auxiliary system

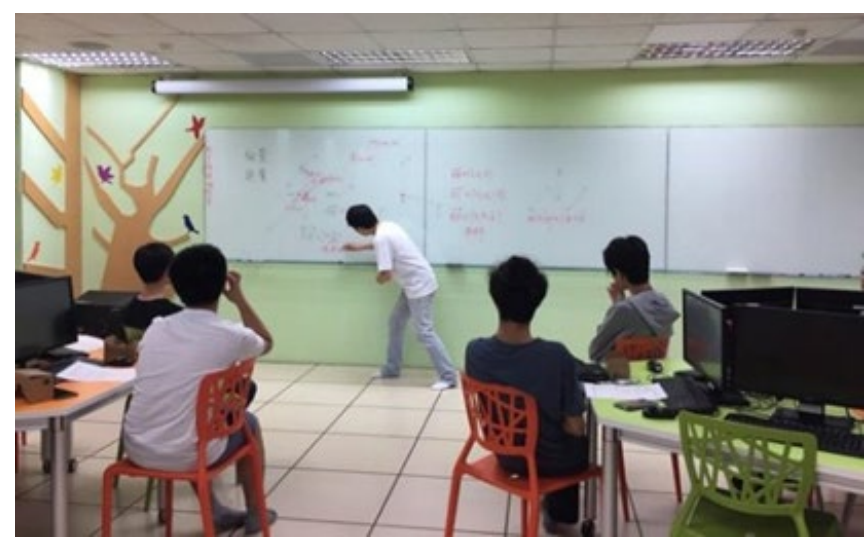

Figure 10. Actual teaching unit

side observed and provided timely guidance (see Figure 9). Students were able to experience the stereoscopic model of Escher's illusion acuity and the compositions and geometric relationship of three intersecting planes via the VR teaching unit.

The teacher's actual teaching unit (Unit 3) was scheduled in the middle of the teaching session and required approximately 40 minutes (Figure 10). This unit involved the actual teaching of systems of linear equations in three variables. The teaching was linked to the VR content.

\section{RESULTS AND DISCUSSION}

Before and after the experiment, the subjects were asked to fill in Bloom's taxonomy questionnaire on systems of linear equations in three variables, which was then used to measure students' learning. Questions relating to satisfaction were also included in the post-test questionnaire to gauge satisfaction with the VR auxiliary system.

\section{Learning Effectiveness and Satisfaction}

The pre-test and post-test questionnaires comprised six multiple choice questions, which sought to assess the first four levels of cognitive domain of Bloom's
Table 3. Bloom's Taxonomy Learning Effectiveness T-test Data

\begin{tabular}{llcccc}
\hline & Group & $\mathrm{N}$ & Mean & $\mathrm{SD}$ & $p$ \\
\cline { 1 - 5 } $\begin{array}{l}\text { Pre- } \\
\text { test }\end{array}$ & Experimental group & 30 & 3.7 & 1.09 & \multirow{2}{*}{.955} \\
\cline { 2 - 5 } $\begin{array}{l}\text { Post- } \\
\text { test }\end{array}$ & Experimental group & 30 & 5.3 & 0.75 & \multirow{2}{*}{.147} \\
\cline { 2 - 5 } & Control group & 12 & 5.3 & 1.15 & \\
\hline
\end{tabular}

Table 4. Data on Learning Effectiveness

\begin{tabular}{lcccc}
\hline Group & $\mathrm{N}$ & $\begin{array}{c}\text { Mean of } \\
\text { pre-test }\end{array}$ & $\begin{array}{r}\text { Mean of } \\
\text { post-test }\end{array}$ & Gap \\
\hline Experimental group & 30 & 3.7 & 5.3 & +1.6 \\
Control group & 12 & 4.2 & 5.3 & +1.1 \\
\hline
\end{tabular}

taxonomy goals. The questions included four imagebased multiple-choice questions and two equationbased multiple-choice questions. The high school mathematics teachers confirmed that the difficulty of the questionnaires was comparable. Each multiple-choice question had four items. Students obtained one point for each correct answer, with a full score of six points and a minimum of zero points.

Table 3 shows the analysis of the experimental data obtained in this research. The data show that the learning effectiveness in either group showed no significant difference before and after the experiment, indicating no significant difference in the learning effectiveness between the two VR auxiliary systems. As no significant difference existed between the two groups before and after the test, we conclude that there was no difference in the pre-test, as no teaching had yet occurred, indicating that the level of learning effectiveness among the students before learning was similar. There was no significant difference in the posttest following teaching, even though the VR auxiliary systems were different. Furthermore, the level of learning effectiveness after learning was found to be similar to that before learning, indicating that the differential in progress made was small. Therefore, we further examined the difference between the average numbers of the two groups before and after the test.

Table 4 presents an analysis of the average learning effectiveness of the two groups. The average score of the experimental group following the pre-test was 3.7, while the average score of the post-test was 5.3, giving an average increase in learning effectiveness of 1.6 points. The average score of the control group of the pre-test was 4.2 , while the average score of the post-test was 5.3, giving an average increase in learning effectiveness of 1.1 points. The results confirm that VR can improve the learning of systems of linear equations in three variables, and the desktop-based VR auxiliary system is superior in improving students' overall learning.

The post-test questionnaire of the experiment also contained eight questions related to satisfaction with the VR auxiliary system. Table 5 presents the satisfaction experiment data. Both groups of students were found to 
Table 5. The Data of Satisfaction

\begin{tabular}{lcc}
\hline Item & $\begin{array}{c}\text { Experimental } \\
\text { Group }\end{array}$ & $\begin{array}{c}\text { Control } \\
\text { Group }\end{array}$ \\
\hline 1. After learning all the contents of this course, I feel very satisfied. & 3.5 & 3.8 \\
2. I like this course very much and hope to have the opportunity to learn more in this area. & 4.0 & 4.1 \\
3. I really like to learn this teaching content. & 3.9 & 4.2 \\
4. The content of this course and the way of explanation make me think it is worth learning. & 3.9 & 3.6 \\
5. The suggestions in this course can give me a sense of encouragement. & 3.9 & 3.8 \\
6. After finishing this course, I hope to learn more about these things. & 3.7 & 3.8 \\
7. After finishing this course, I have a sense of accomplishment. & 4.1 & 3.8 \\
8. I am very happy to have the opportunity to study this course. & $30.6 / 40$ & $31.4 / 40$ \\
\hline Total &
\end{tabular}

be highly satisfied with the teaching materials. The average score for each question was greater than 3 (total score of 5), and the total score for eight questions was also higher than 30 (out of a maximum total score of 40). Moreover, the satisfaction of the all-in-one VR auxiliary system was found to be higher than that of the experimental group. The overall results show that students were generally accepting of the VR auxiliary system and suggest that VR is suitable for use in the teaching of systems of linear equations in three variables. This result concords with the results of Bogusevschi et al. (2019), which showed that more than $74 \%$ of students enjoyed learning using a desktop-based VR-VL application.

\section{Observation and Interview}

Most of the students appeared to be excited when they first encountered the VR, even though the context of the contact was a mathematics class. The geometrically dislocated interactive animation converted from the first unit of Escher's optical illusion aroused enthusiasm among students and a sense of a challenge. Most of the students actively used the rotation angle and deconstruction to observe the various constitutions of the three planes after the optical illusion of the first unit and the VR three planes of the second unit to fully understand the various intersecting situations of the three planes. Some students even reflected that they did not expect mathematics to be introduced into equational learning through optical illusion. Since they were engrossed by the optical illusion, when exploring the composition of the three planes, they paid greater attention to the task at hand.

The teachers also reflected that after the students learned the eight intersecting situations formed by three planes through VR, they no longer had to worry about the students' inability to understand the composition of the three planes when covering systems of linear equations in three variables. Students were found to be more interested in understanding the relationship between VR and mathematical equations. Finally, the last two VR units of gamification, combined with the time limit and the tension of train impact, were found to be stimulating and were able to foster confidence in the students who came to feel adept at problem solving. These results are supported by the related literature (McKnight et al., 2016; Yüksel \& Adigüzel, 2012).

Furthermore, researchers and teachers observed that student participation was good and students showed great enthusiasm. In terms of participation, teachers felt that enthusiasm among students was improved and that they were frequently more comfortable asking questions when required and confident when facing challenging problems. Students were interested to know if there were other units that could be learned in a similar fashion and expressed excitement at the prospect of experiencing this type of teaching again in the future. Studies have consistently shown that VR technology is beneficial to students when it is correctly adapted to the classroom (Black, 2017; Kickmeier-Rust et al., 2019; Zhou et al., 2018).

After the interviews were conducted, most students appeared to find learning abstract mathematics through VR fun and novel. These results align with those of Manseur (2005), who showed that VR can be used for teaching abstract topics such as molecular systems, galaxies, and other astronomy topics. It is therefore recommended that VR be applied to other subjects in the future.

\section{CONCLUSION}

This study explored whether it is appropriate to use VR technology to assist traditional mathematics teaching and determined its impact on the effectiveness of mathematics learning. The teaching theme of this study focuses on the design of materials for systems of linear equations in three variables. The study considers how best to use VR to present more abstract learning topics in real life and incorporate fun, knowledge, and interactivity into learning, thereby making mathematics more attractive to students. The study also analyzed the impact of this teaching model on learning.

The results of data analysis and interviews show that the digital teaching materials produced in VR combined with the traditional mathematics curriculum learning methods were well-received and that learning effectiveness was also improved. The effect of the 
desktop-based VR auxiliary system was found to be better than that of the all-in-one VR auxiliary system, since the desktop-based VR equipped with highefficiency display and better control to allow students to have a higher level of immersion. In the future, it is hoped that this research will be harnessed to further optimize teaching materials (application of VR) so that they may be combined with traditional teaching. It is also hoped that the result of the study will help to achieve complementarity between teachers and teaching materials and bring more learning benefits to students by continuously improving their ability to learn.

Furthermore, with the progress of technology, the development of all-in-one VR devices will increase display performance and control freedom. And its convenient portability and display advantages will surpass desktop-based VR devices in the near future. Digital teaching has gradually become obvious in the epidemic era, and the use of high-tech teaching will also be the trend of education. This study explores the impact of learning effectiveness caused by the effectiveness and convenience of virtual reality equipment, and only provides reference for current teaching use.

Funding: This research is partially supported by the "Project of the development, promotion and demonstration of the VR/AR teaching materials", sponsored by the Ministry of Education, Taiwan, R.O.C.

Acknowledgements: We would like to thank Uni-edit (www.uniedit.net) for editing and proofreading this manuscript.

Declaration of interest: No conflict of interest is declared by author.

\section{REFERENCES}

Abdullah, F., Kassim, M. H. B., \& Sanusi, A. N. Z. (2017). Go virtual: Exploring augmented reality application in representation of steel architectural construction for the enhancement of architecture education. Advanced Science Letters, 23(2), 804-808. https: / / doi.org/10.1166/as1.2017.7449

Amer, A., \& Peralez, P. (2014). Affordable altered perspectives: Making augmented and virtual reality technology accessible. IEEE global humanitarian technology conference (GHTC 2014) (pp. 603-608).

https://doi.org/10.1109/GHTC.2014.6970345

Amin, A., Gromala, D., Tong, X., \& Shaw, C. (2016). Immersion in cardboard VR compared to a traditional head-mounted display. In International Conference on Virtual, Augmented and Mixed Reality (pp. 269-276). Springer. https://doi.org/10.1007/ 978-3-319-39907-2_25

Anderson, L. W., Krathwohl, D. R., Airasian, P. W., Cruikshank, K. A., Mayer, R. E., Pintrich, R. R., Raths, J., \& Wittrock, M.C. (2001). A taxonomy for learning teaching, and assessing: A revision of Bloom's. Longman.
Ball, C., \& Johnsen, K. (2016). An accessible platform for everyday educational virtual reality. Everyday virtual reality (WEVR), 2016 IEEE 2nd workshop on IEEE (pp. 26-31). https:// doi.org/10.1109/WEVR. 2016.7859540

Black, E. R. (2017). Learning then and there: an exploration of virtual reality in $k-12$ history education. (Unpublished doctoral thesis), The University of Texas: Texas.

Bogusevschi, D., Muntean, C. H., \& Muntean, G.-M. (2020). Teaching and learning physics using 3D virtual learning environment: A case study of combined virtual reality and virtual laboratory in secondary school. Journal of Computers in Mathematics and Science Teaching, 39(1), 5-18.

Bogusevschi, D., Muntean, H. C., \& Muntean, G. M. (2019). Teaching and learning physics using 3D virtual learning environment: A case study of combined virtual reality and virtual laboratory in secondary school. Journal of Computers in Mathematics and Science Teaching, 39(1), 5-18.

Brinson, J. R. (2015). Learning outcome achievement in non-traditional (virtual and remote) versus traditional (handson) laboratories: A review of the empirical research. Computers $\mathcal{E}$ Education, 87, 218237. https:/ / doi.org/10.1016/j.compedu.2015.07.003

Brown, J. S., Collins, A., \& Duguid, P. (1989). Situated cognition and the culture of learning. Educational Researcher, 18(1), 32-41. https://doi.org/10.3102/ 0013189X018001032

Burdea, G. (1993, April). Virtual Reality Systems and Applications. In Electro '93 International Conference, Short Course, Edison, NJ, pp. 164-165.

Castelvecchi, D. (2016). Low-cost headsets boost virtual reality's lab appeal. Nature, 533, 153-154. https:/ / doi.org/10.1038/533153a

Chen, C.-M., \& Hsu, S.-H. (2008). Personalized intelligent mobile learning system for supportive effective English learning. Educational Technology and Society Journal, 11(3), 153-180.

Cheng, K., \& Hong, S. (2018, October 1). Will AR / VR affect future corporate competition strategies? EET Taiwan. https://www.eettaiwan.com/news/ article/20181001NT31-AR-VR

Degli, E., Geronazzo, M., Vercovi, D., Nordahl, R., Serafin, S., Ludovico, L. A., \& Avanzini, F. (2019). Mobile virtual reality for musical genre learning in primary education. Computers $\mathcal{E}$ Education, 139, 102-117. https:/ / doi.org/10.1016/j.compedu.2019.04.010

Fan, X., \& Geelan D. (2012, October). Integrating information technology and science education for the future: A theoretical review on the educational use of interactive simulations. In J. Pagram \& P. 
Newhouse (Eds.), Proceedings of the 2012 Australian Computers in Education Conference (ACEC), 1-9.

Freina, L., \& Ott, M. (2015). A literature review on immersive virtual reality in education: State of the art and perspectives. eLearning and Software for Education (eLSE). Bucharest.

Heradio, R., de la Torre, L., Galan, D., Cabrerizo, F. J., Herrera-Viedma, E., \& Dormido, S. (2016). Virtual and remote labs in education: A bibliometric analysis. Computers and Education, 98, 14-38. https:// doi.org/10.1016/j.compedu.2016.03.010

Hsu, Y. C. (2020). Exploring the Learning Motivation and Effectiveness of Applying Virtual Reality to High School Mathematics. Universal Journal of Educational Research, 8(2), 438-444. https://doi.org/10.13189/ujer.2020.080214

Hsu, Y. C., Lin, Y. C., Lin, Y. C., Chang, W. H., \& Chen, C. C. (2018). Investigating the learning effectiveness of applying virtual reality to high school mathematics - A case study of the system of linear equations in three unknowns. 2018 Taiwan Academic Network Conference (pp. 2507-2511). https:/ / doi.org/10.6861/TANET.201810.0464

Innocenti, E. D., Geronazzo, M., Vescovia, D., Nordahlb, R., Serafinb, S., Ludovicoc, L. A., \& Avanzinic, F. (2019). Mobile virtual reality for musical genre learning in primary education. Computers $\mathcal{E}$ Education, 139, 102-117. https://doi.org/10.1016/ j.compedu.2019.04.010

Jang, S., Vitale, J. M., Jyung, R. W., \& Black, J. B. (2017). Direct manipulation is better than passive viewing for learning anatomy in a three-dimensional virtual reality environment. Computers $\mathcal{E}$ Education, 106, 150-165.

https://doi.org/10.1016/j.compedu.2016.12.009

Kaufmann, H. (2006). The potential of augmented reality in dynamic geometry education [Paper presentation]. 12th International Conference on Geometry and Graphics, Salvador, Brazil.

Kebritchi, M., Hirumi, A., \& Bai, H. (2010). The effects of modern mathematics computer games on mathematics achievement and class motivation. Computers $\mathcal{E}$ Education, 55(2), 427-443. https:/ / doi.org/10.1016/j.compedu.2010.02.007

Kickmeier-Rust M.D., Hann P., \& Leitner M. (2019). Increasing learning motivation: An empirical study of VR effects on the vocational training of bank clerks. In E. van der Spek, S. Göbel, E. L. Do, E. Clua, \& J. Baalsrud Hauge (Eds.), Entertainment Computing and Serious Games. ICEC-JCSG 2019. Lecture Notes in Computer Science (vol. 11863). Springer. https://doi.org/10.1007/978-3-03034644-7_9

Krathwohl, D. R. (2002). A revision of Bloom's taxonomy: an overview. Journal of Theory into
Practice, 41(4), 212-219. https://doi.org/10.1207/ s15430421tip4104_2

Lee, E. A., Wong, K. W., \& Fung, C. C. (2010). How does desktop virtual reality enhance learning outcomes? A structural equation modeling approach. Computers $\mathcal{E}$ Education, 55, 1424-1442. https://doi.org/10.1016/j.compedu.2010.06.006

Lee, S. H., Sergueeva, K., Catangui, M., \& Kandaurova, M. (2017). Assessing google cardboard virtual reality as a content delivery system in business classrooms. Journal of Education for Business, 92(4), 153-160, https:/ / doi.org/10.1080/08832323.2017.1308308

Lim, D. H., Han, S. J., Oh, J., \& Jang, C. S. (2019). Application of virtual and augmented reality for training and mentoring of higher education instructors. Handbook of research on virtual training and mentoring of online instructors (pp. 325-344). IGI Global. https://doi.org/10.4018/978-1-5225-63228.ch015

Liu, T. Y. (2009). A context-aware ubiquitous learning environment for language listening and speaking. Journal of Computer Assisted Learning, 25(6), 515-527. https:// doi.org/10.1111/j.1365-2729.2009.00329.x

Looi, C. K., Zhang, B., Chen, W., Seow, P., Chia, G., Norris, C., \& Soloway, E. (2011). 1: 1 mobile inquiry learning experience for primary science students: a study of learning effectiveness. Journal of Computer Assisted Learning, 27(3), 269-287. https://doi.org/ 10.1111/j.1365-2729.2010.00390.x

Manseur, R. (2005- October). Virtual reality in science and engineering education. 35th ASEE/IEEE Frontiers in Education Conference, Indianapolis, IN.

Martin, G., Gollan, P. J., \& Grigg, K. (2011). Is there a bigger and better future for employer branding? Facing up to innovation, corporate reputations and wicked problems in SHRM. The International Journal of Human Resource Management, 22(17), 3618-3637. https:/ / doi.org/10.1080/09585192.2011.560880

McKnight, K., O’Malley, K., Ruzic, R., Horsley, M. K., Franey, J. J., \& Bassett, K. (2016). Teaching in a digital age: How educators use technology to improve student learning. Journal of Research on Technology in Education, 48(3), 194-211. https:/ / doi.org/10.1080/15391523.2016.1175856

McLellan, H. (1994). Situated learning: Continuing the conversation. Educational Technology, 34(10), 7-8.

Merchant, Z., Goetz, E., Keeney-Kennicutt, W., Kwok, O., Cifuentes, L., \& Davis, T. J. (2012). The learner characteristics, features of desktop 3D virtual reality environments, and college chemistry instruction: a structural equation modeling analysis. Computers $\mathcal{E}$ Education, 59, 551-568. https:/ / doi.org/10.1016/j.compedu.2012.02.004 
Moody, D. L., \& Sindre, G. (2003). Evaluating the effectiveness of learning interventions: An information systems case study. ECIS 2003 Proceedings. 80.

Moro, C., Štromberga, Z., Raikos, A., \& Stirling, A. (2017). Virtualisation Devices for Student Learning: Comparison between Desktop-Based (Oculus Rift) and Mobile-Based (Gear VR) Virtual Reality in Medical and Health Science Education. Australasian Journal of Educational Technology, 33(6), 1-10. https:/ / doi.org/10.14742/ajet.3840

Pasqualotti, A., \& Freitas, C. M. D. S. (2002). MAT3D: a virtual reality modeling language environment for the teaching and learning of mathematics. CyberPsychology \& Behavior, 5(5), 409-422. https:// doi.org/10.1089/109493102761022832

Pelargos, P. E., Nagasawa, D. T., Lagman, C., Tenn, S., Demos, J. V., Lee, S. J., Bui, T. T., Barnette, N. E., Bhatt, N. S., Ung, N., Bari, A., Martin, N. A., \& Yang, I. (2017). Utilizing virtual and augmented reality for educational and clinical enhancements in neurosurgery. Journal of Clinical Neuroscience, 35, 14. https:// doi.org/10.1016/j.jocn.2016.09.002

Ruchter, M., Klar, B., \& Geiger, W. (2010). Comparing the effects of mobile computers and traditional approaches in environmental education. Computers $\mathcal{E}$ Education, 54(4), 1054-1067. https://doi.org/ 10.1016/j.compedu.2009.10.010

Ruijten, P. A. M., Kruyt-Beursken, E., \& IJsselsteijn, W. A. (2018). Towards the simplicity of complex interfaces: Applying ephemeral adaptation to enhance user performance and satisfaction. In J. Ham, A. Spagnolli, B. Blankertz, L. Gamberini, \& G. Jacucci (Eds.), Symbiotic interaction (pp. 86-97). Springer International Publishing. https:/ / doi.org /10.1007/978-3-319-91593-7_10

Sherman, W. R., \& Craig, A. B. (2003). Understanding virtual reality. Morgan Kaufmann Publishers.
Simsek, I. (2016). The effect of 3D virtual learning environment on secondary school third grade students' attitudes toward mathematics. Turkish Online Journal of Educational Technology (TOJET), 15(3), 162-168.

Tibaldi, A., Bonali, F.L., Vitello, F., Delage, E., Nomikou, P., Antoniou, V., Becciani, U., Van Wyk de Vries, B., Krokos, M., \& Whitworth, M. (2020). Real worldbased immersive virtual reality for research, teaching and communication in volcanology. Bulletin of Volcanology, 82(5), 36-47. https:/ / doi.org/10.1007/s00445-020-01376-6

Tseng, A. (2018, January 3). VR will be liberated from computers and mobile phones, and HTC and Oculus will take the lead in ushering in virtual reality 2.0. https:/ / www.bnext.com.tw/article/47674/2018would-be-the-year-for-standalone-vr

Wexelblat, A. (Ed.). (2014). Virtual reality: Applications and explorations. Academic Press.

Wu, H. (2017, December 15). HTC Vive Focus pre-order hot sale. https:/ / m.ctee.com.tw/ focus/kjmd/170021

Yildirim, B., Sahin-Topalcengiz, E., Arikan, G., \& Timur, S., (2020). Using virtual reality in the classroom: Reflections of STEM teachers on the use of teaching and learning tools. Journal of Education in Science, Environment and Health, 6(3), 231-245. https:// doi.org/10.21891/jeseh.711779

Yuksel, İ., \& Adıgüzel, A. (2012). Evaluation of teachers' instructional technologies integration skills: a qualitative need analysis for new pedagogical approaches. Necatibey Faculty of Education Electronic Journal of Science and Mathematics Education, 6(1), 265-286.

Zhou, Y., Ji, S., Xu, T., \& Wang, Z. (2018). Promoting knowledge construction: a model for using virtual reality interaction to enhance learning. Procedia Computer Science, 130(2018), 239-246. https:/ / doi.org/10.1016/j.procs.2018.04.035

\section{http://www.ejmste.com}

